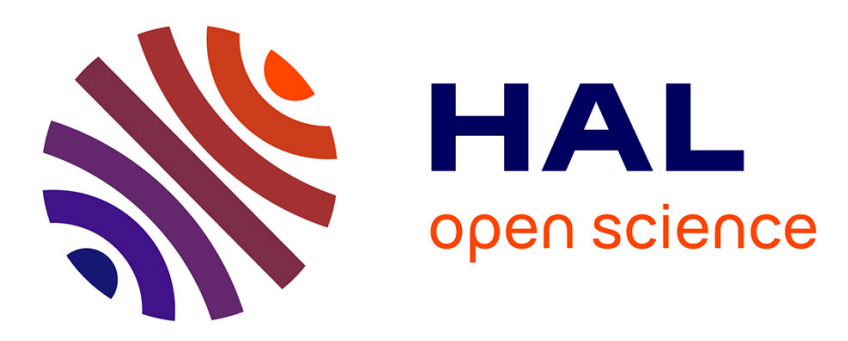

\title{
Stoichiometric methane conversion to ethane using photochemical looping at ambient temperature
}

Xiang Yu, Vladimir L Zholobenko, Simona Moldovan, Di Hu, Dan Wu, Vitaly

Ordomsky, Andrei y Khodakov

\section{- To cite this version:}

Xiang Yu, Vladimir L Zholobenko, Simona Moldovan, Di Hu, Dan Wu, et al.. Stoichiometric methane conversion to ethane using photochemical looping at ambient temperature. Nature Energy, 2020, 5 (7), pp.511-519. 10.1038/s41560-020-0616-7 . hal-03052393

\section{HAL Id: hal-03052393 \\ https://hal.science/hal-03052393}

Submitted on 11 Dec 2020

HAL is a multi-disciplinary open access archive for the deposit and dissemination of scientific research documents, whether they are published or not. The documents may come from teaching and research institutions in France or abroad, or from public or private research centers.
L'archive ouverte pluridisciplinaire HAL, est destinée au dépôt et à la diffusion de documents scientifiques de niveau recherche, publiés ou non, émanant des établissements d'enseignement et de recherche français ou étrangers, des laboratoires publics ou privés. 
archives-ouvertes

\section{Stoichiometric methane conversion to ethane using photochemical looping at ambient temperature}

Xiang Yu, Vladimir Zholobenko, Simona Moldovan, Di Hu, Dan Wu, Vitaly Ordomsky, Andrei Khodakov

\section{To cite this version:}

Xiang Yu, Vladimir Zholobenko, Simona Moldovan, Di Hu, Dan Wu, et al.. Stoichiometric methane conversion to ethane using photochemical looping at ambient temperature. Nature Energy, Nature Publishing Group, 2020, 5 (7), pp.511-519. 10.1038/s41560-020-0616-7 . hal-03052393

HAL Id: hal-03052393

https://hal.archives-ouvertes.fr/hal-03052393

Submitted on 11 Dec 2020

HAL is a multi-disciplinary open access archive for the deposit and dissemination of scientific research documents, whether they are published or not. The documents may come from teaching and research institutions in France or abroad, or from public or private research centers.
L'archive ouverte pluridisciplinaire HAL, est destinée au dépôt et à la diffusion de documents scientifiques de niveau recherche, publiés ou non, émanant des établissements d'enseignement et de recherche français ou étrangers, des laboratoires publics ou privés. 


\title{
Stoichiometric methane conversion to ethane using photochemical looping at ambient temperature
}

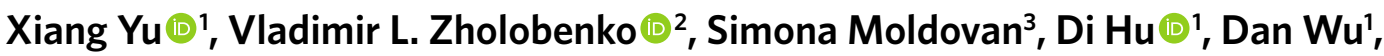 \\ Vitaly V. Ordomsky ${ }^{1 凶}$ and Andrei Y. Khodakov ${ }^{1 凶}$
}

\begin{abstract}
Methane activation and utilization are among the major challenges of modern science. Methane is potentially an important feedstock for manufacturing value-added fuels and chemicals. However, most known processes require excessive operating temperatures and exhibit insufficient selectivity. Here, we demonstrate a photochemical looping strategy for highly selective stoichiometric conversion of methane to ethane at ambient temperature over silver-heteropolyacid-titania nanocomposites. The process involves a stoichiometric reaction of methane with highly dispersed cationic silver under illumination, which results in the formation of methyl radicals. Recombination of the generated methyl radicals leads to the selective, and almost quantitative, formation of ethane. Cationic silver species are simultaneously reduced to metallic silver. The silver-heteropolyacid-titania nanocomposites can be reversibly regenerated in air under illumination at ambient temperature. The photochemical looping process achieves a methane coupling selectivity of over $90 \%$, a quantitative yield of ethane of over $9 \%$, high quantum efficiency $(3.5 \%$ at $362 \mathrm{~nm})$ and excellent stability.
\end{abstract}

M ethane is the main component of natural and shale gas, methane clathrates and biogas, and is a potent greenhouse gas. About $90 \%$ of methane is currently burnt in various combustion processes, releasing carbon dioxide into the atmosphere ${ }^{1-7}$. Finding ways to efficiently convert methane into fuels and chemicals is important for the rational utilization of fossil and renewable energy feedstocks, as well as for reducing the emission of greenhouse gases. Methane is a highly stable molecule; it has no functional groups and a very high $\mathrm{C}-\mathrm{H}$ bond enthalpy $\left(439 \mathrm{~kJ} \mathrm{~mol}^{-1}\right)$. Methane is also inert relative to acid attack and has a very low proton affinity $\left(544 \mathrm{~kJ} \mathrm{~mol}^{-1}\right)$ and acidity $\left(\mathrm{p} K_{\mathrm{a}}=40\right)$. Therefore, direct chemical conversion of methane to value-added chemicals and fuels remains a formidable challenge for modern science ${ }^{8-10}$.

Commercial technologies of methane utilization, other than combustion, are rather limited. They involve methane steam reforming, partial oxidation, autothermal reforming or the Andrussow reaction $^{11-13}$. The non-commercial routes for methane conversion can be divided into oxidative and non-oxidative routes ${ }^{8-21}$. The non-oxidative routes, such as methane aromatization, result in substantial carbon deposition, while the oxidative routes, such as methane thermocatalytic coupling and methane partial oxidation, usually suffer from insufficient selectivity and abundant production of $\mathrm{CO}_{2}$. Most of the known methane conversion reactions require very high temperatures $\left(>800^{\circ} \mathrm{C}\right)$. Generally, these thermochemical processes are accompanied by $\mathrm{CO}_{2}$ emissions arising from the combustion of fossil fuels utilized to maintain the reactor at high temperatures ${ }^{18-23}$.

Photocatalytic non-oxidative coupling of methane with very low quantum efficiencies and yields was observed over silica, highly dispersed $\mathrm{Ga}$ or Ce species ${ }^{24-26}$. Activation of methane over $\mathrm{Zn}^{2+} /$ ZSM-5 and Ga ${ }^{3+} /$ EST-10 photocatalysts has been reported, with the photocatalytic activity attributed to the presence of extra-framework zinc cations and Ti-OH groups on titanate wires ${ }^{27,28}$. Photocatalytic non-oxidative coupling of methane has been observed when exploiting the surface plasmon effect of $\mathrm{Au}\left(\right.$ ref. ${ }^{29}$ ) or $\mathrm{Ga}$ and $\mathrm{Pt}$ photocatalysts supported on $\mathrm{TiO}_{2}-\mathrm{SiO}_{2}\left(\right.$ ref. ${ }^{30}$ ). Methane photocatalytic coupling with higher quantum efficiencies has been reported over $\mathrm{Pd} / \mathrm{TiO}_{2}$ catalysts $^{31,32}$. A photoelectrochemical system has also been used ${ }^{33}$; however, the maximum selectivity of methane coupling to ethane was below $53 \%$. Thus, the major challenges of methane coupling in both thermocatalytic and photocatalytic routes are insufficient selectivities and yields of target products, large production of $\mathrm{CO}_{2}$ and poor catalyst stability.

In this work, we demonstrate a photochemical looping concept for methane conversion to ethane at ambient temperature under irradiation using silver-heteropolyacid-titania nanocomposites, which achieves high selectivity (>90\%), notable yield of $\mathrm{C}_{2} \mathrm{H}_{6}$ $(>9 \%)$, high quantum efficiency $(\mathrm{QE}=3.5 \%$ at $362 \mathrm{~nm})$ and excellent stability.

\section{Photochemical coupling of methane over metal nanocomposites}

First, we investigated photochemical conversion of methane over $\mathrm{TiO}_{2}$, phosphotungstic acid (HPW) and $\mathrm{HPW} / \mathrm{TiO}_{2}$ composites containing different metals in a batch photoreactor (Supplementary Fig. 1). No methane conversion was observed in the absence of light on all the studied solids. In agreement with previously reported data ${ }^{34}, \mathrm{CO}_{2}$ was detected as the only reaction product after the exposure of $\mathrm{TiO}_{2}$, HPW and $\mathrm{HPW} / \mathrm{TiO}_{2}$ composites to methane at ambient temperature using illumination (Fig. 1). As the gaseous phase in the reactor contained only methane, but no oxygen or other gases, the oxygen for the methane oxidation to $\mathrm{CO}_{2}$ must have been provided by the solids $\left(\mathrm{TiO}_{2}\right.$, HPW and so on) present in the photoreactor.

Methane conversion over the metal containing $\mathrm{HPW} / \mathrm{TiO}_{2}$ composites yielded both $\mathrm{C}_{2} \mathrm{H}_{6}$ and $\mathrm{CO}_{2}$ (Fig. 1a), along with traces of $\mathrm{CO}$, while no hydrogen or oxygen was detected. Lower methane coupling production was observed over the solids containing $\mathrm{Cu}, \mathrm{Zn}$ and $\mathrm{Bi}$. 


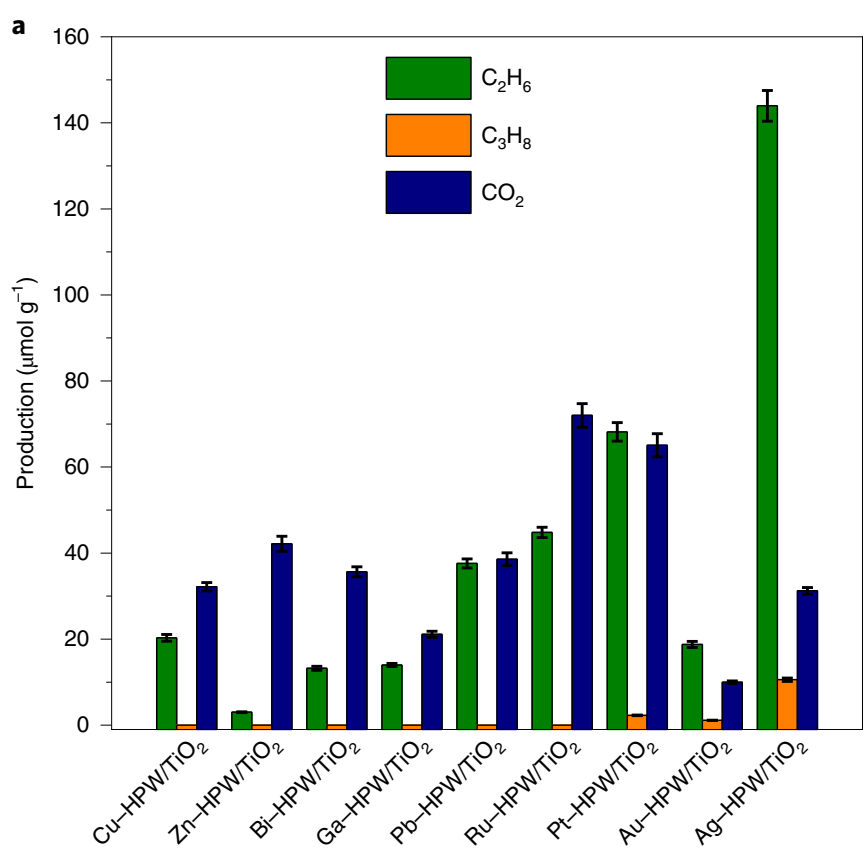

b

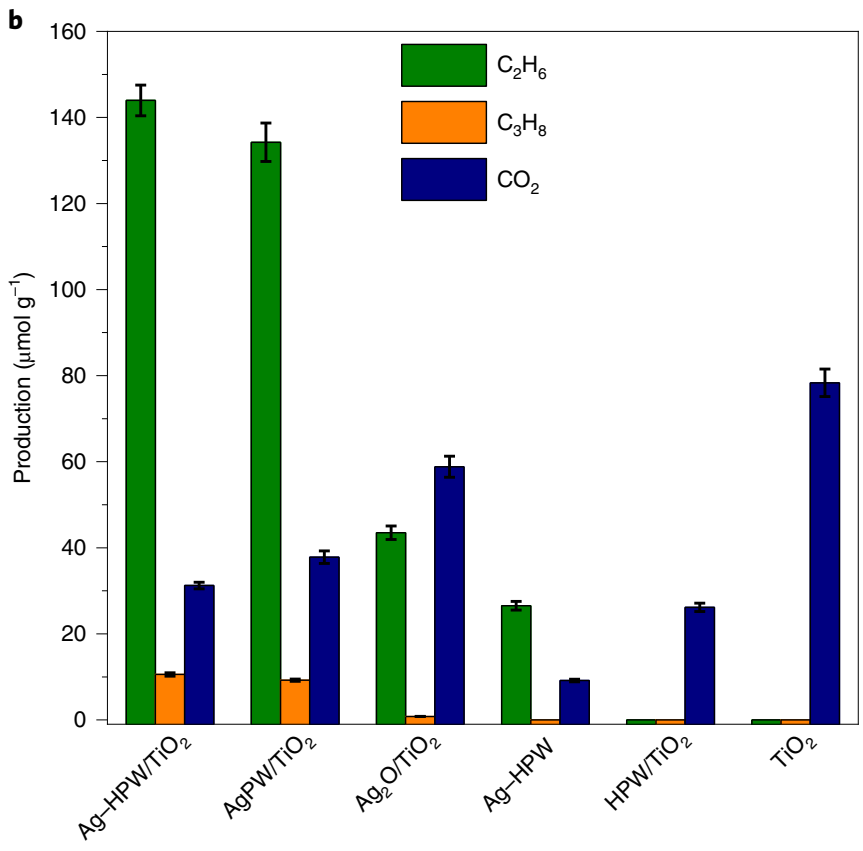

Fig. 1 | Photochemical coupling of methane on different materials. a, Metal-HPW/ $\mathrm{TiO}_{2}$ composites. b, $\mathrm{TiO}_{2}-, \mathrm{HPW}$ - and Ag-containing samples. Note that the data for $\mathrm{Ag}-\mathrm{HPW} / \mathrm{TiO}_{2}$ are shown in both $\mathbf{a}$ and $\mathbf{b}$. Reaction conditions were nanocomposite, 0.1 g; gas phase pressure, $\mathrm{CH}_{4}$, $0.3 \mathrm{MPa}$; irradiation time, $7 \mathrm{~h}$. The selectivity was calculated on a molar carbon basis. The experiments in each case were performed three times. The error bars represent the standard deviation. The relative standard deviation is within $5 \%$.

A higher production rate and selectivity to ethane were observed on the Pt- and Ag-based HPW/ $/ \mathrm{TiO}_{2}$ nanocomposites. Besides ethane, small amounts of propane were detected. Remarkably, compared to the Pt- and Au-based counterparts, $\mathrm{Ag}-\mathrm{HPW} / \mathrm{TiO}_{2}$ demonstrated a much higher ethane selectivity and methane conversion rate. The overall selectivity of methane coupling to ethane and propane is greater than $90 \%$ on the $\mathrm{Ag}-\mathrm{HPW} / \mathrm{TiO}_{2}$ nanocomposite. Note that the silver salt of heteropolyacid deposited on $\mathrm{TiO}_{2}$ (AgPW/ $\mathrm{TiO}_{2}$ ) exhibits similar performance in methane coupling (Fig. 1b). After exposure to methane in the presence of light, the Ag-HPW/ $\mathrm{TiO}_{2}$ sample becomes black, indicating a possible photochemical transformation of oxidized silver species to a silver metallic phase (Fig. 2a,b).

Apart from gas chromatography (GC) analysis, the composition of the gaseous phase during the methane conversion was followed by in situ Fourier transform infrared spectroscopy (FTIR; Supplementary Fig. 2). Only methane was detected at the initial period of reaction. Gaseous $\mathrm{CO}_{2}$ and $\mathrm{H}_{2} \mathrm{O}$ were identified in the FTIR cell at later stages, with the intensity of the $\mathrm{H}_{2} \mathrm{O}$ and $\mathrm{CO}_{2}$ bands noticeably increasing with the reaction time.

To confirm the importance of irradiation for methane coupling, we exposed the $\mathrm{Ag}-\mathrm{HPW} / \mathrm{TiO}_{2}$ nanocomposite, in the absence of irradiation, to methane at $100^{\circ} \mathrm{C}$. No methane conversion was observed in the absence of light. To evaluate the effect of chemisorbed water and oxygen on methane conversion, the Ag-HPW/ $\mathrm{TiO}_{2}$ composite was heated overnight at $80^{\circ} \mathrm{C}$. No effect of this dehydration pretreatment on the reaction selectivity was observed.

We attempted to optimize the chemical composition of silver-containing nanocomposites by varying the silver content, $\mathrm{HPW} / \mathrm{TiO}_{2}$ ratio, supports $\left(\mathrm{TiO}_{2}, \mathrm{SiO}_{2}, \mathrm{~g}_{-} \mathrm{C}_{3} \mathrm{~N}_{4}\right.$ and $\left.\mathrm{BiVO}_{4}\right)$ and heteropolyacid (phosphotungstic, phosphomolybdic and silicotungstic). The addition of even $1 \mathrm{wt} \%$ of silver to $\mathrm{HPW} / \mathrm{TiO}_{2}$ results in a major increase in the rate of methane coupling. The highest rate was observed at the Ag content of $6.0 \mathrm{wt} \%$; the rate then decreased at higher Ag loadings (Supplementary Fig. 3). In the sample with $6 \mathrm{wt} \% \mathrm{Ag}$ content, the optimized performance was obtained at the $\mathrm{HPW} / \mathrm{TiO}_{2}$ ratio of 0.6 , while the methane coupling rate decreased at higher $\mathrm{HPW} / \mathrm{TiO}_{2}$ ratios (Supplementary Fig. 4). One of the reasons for the lower methane coupling rate could be the decline of the specific surface area measured by the Brunauer-EmmettTeller method (BET) at the higher content of heteropolyacid (Supplementary Table 1). We observed ethane production, but with low efficiency over silver species dispersed in silica and other insulator supports (Supplementary Fig. 5). This is also consistent with previous research ${ }^{35,36}$, reporting small amounts of ethane forming from methane over silver-containing zeolites. The amounts of ethane, propane and carbon dioxide produced over the silver-titania nanocomposite containing different heteropolyacids as a function of reaction time are shown in Supplementary Fig. 6. Ethane and propane are produced with higher yield only in the presence of HPW.

Thus, a major increase in the $\mathrm{C}_{2} \mathrm{H}_{6}$ production from methane only occurs when the nanocomposite combines together $\mathrm{TiO}_{2}$, HPW and Ag. HPW has been discovered previously ${ }^{37-41}$ as highly efficient for the transfer of holes and electrons from $\mathrm{TiO}_{2}$. The photochemical performance of the $\mathrm{HPW} / \mathrm{TiO}_{2}$ nanocomposite can be enhanced by a $\mathrm{p}-\mathrm{n}$ semiconductor heterojunction, created by the addition of a semiconductor with lower levels of valence and conduction bands to $\mathrm{TiO}_{2}$. One of the conditions for heterojunction is close contact but distinct separation of two semiconductor phases. The valence and conduction bands of phosphotungstic acid are located at a lower energy than that for $\mathrm{TiO}_{2}$, which may result in a higher electron flux from $\mathrm{TiO}_{2}$ onto HPW (Supplementary Fig. 7). In the presence of irradiation and an electric field, the electrons are transferred to the conduction band of the p-type semiconductor (HPW) and the holes to the valence band of the n-type semiconductor $\left(\mathrm{TiO}_{2}\right)$. This heterojunction increases the electron concentration in HPW and hole concentration in $\mathrm{TiO}_{2}$. Methane oxidation is then improved by the higher concentration of holes on the surface of $\mathrm{TiO}_{2}$, while silver reduction is enhanced by the higher electron density over HPW. Note that ethane also forms over Ag$\mathrm{HPW}$ though at a lower rate compared to the $\mathrm{Ag}-\mathrm{HPW} / \mathrm{TiO}_{2}$ nanocomposite. This emphasizes an additional important role of HPW in dispersing silver species. 

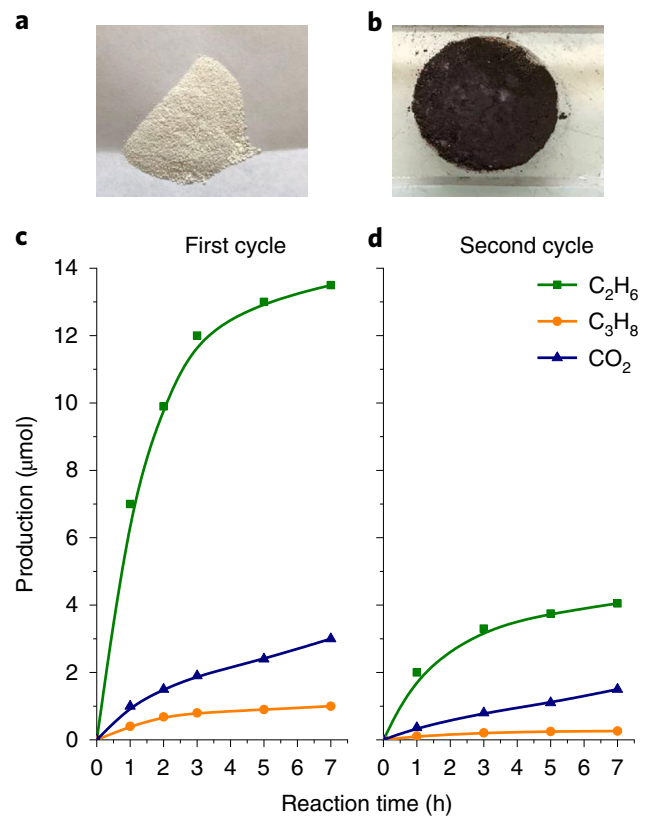

b

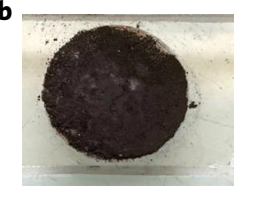

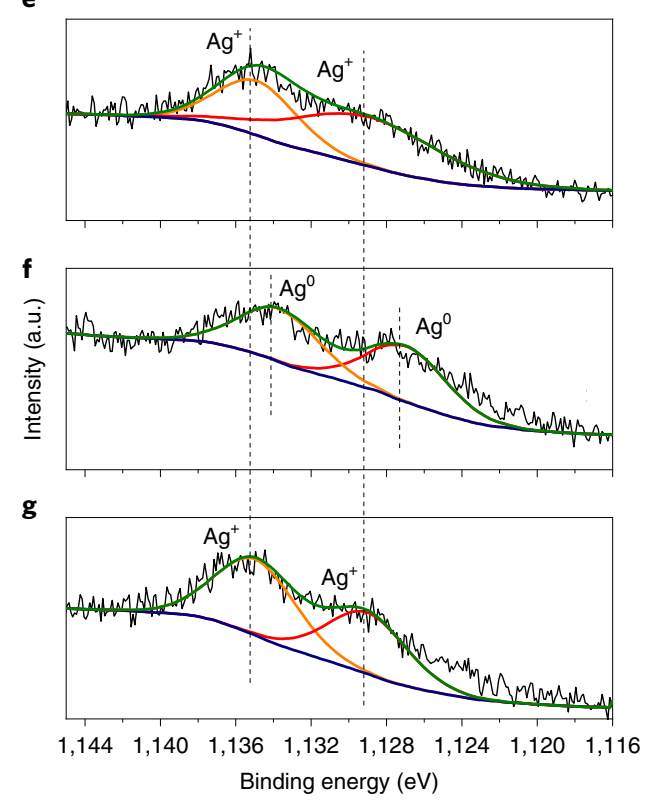

g

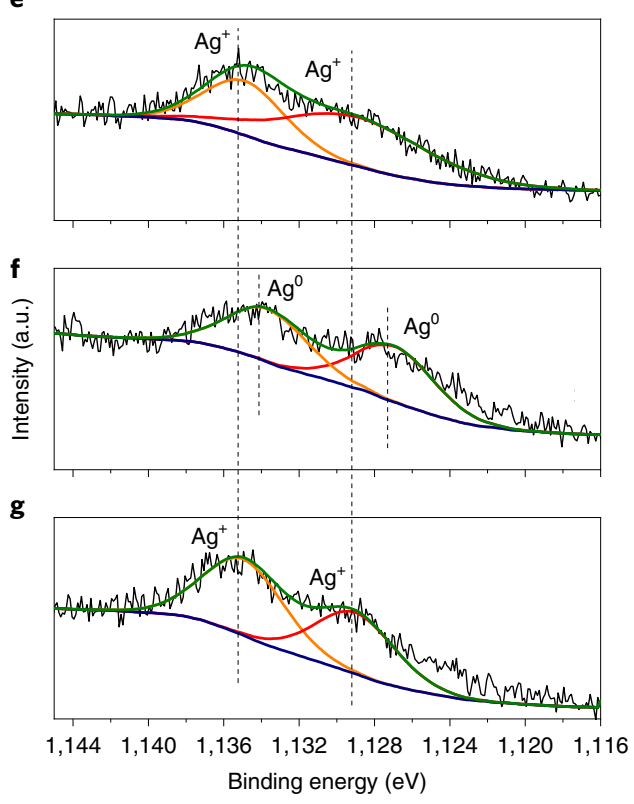

h

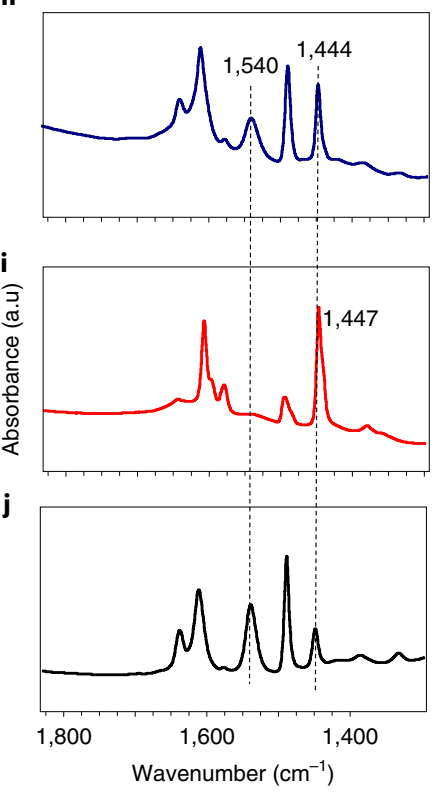

Fig. 2 | Changes of Ag-HPW/TiO ${ }_{2}$ after methane photochemical coupling. a, Photo of the fresh nanocomposite. $\mathbf{b}$, Photo of the spent nanocomposite. $\mathbf{c}, \mathbf{d}$, Methane photochemical coupling on fresh (c) and spent (d) $\mathrm{Ag}-\mathrm{HPW} / \mathrm{TiO}_{2}$. The lines are guides to the eye. Reaction conditions were nanocomposite, $0.1 \mathrm{~g}$ and gas phase pressure, $\mathrm{CH}_{4}, 0.3 \mathrm{MPa}$. e-g, $\mathrm{Ag} \mathrm{M} \mathrm{M}_{4} \mathrm{VV}$ Auger spectra of $\mathrm{Ag}-\mathrm{HPW} / \mathrm{TiO}_{2}$ : fresh sample (e), sample treated in $0.3 \mathrm{MPa} \mathrm{CH}_{4}$ under $400 \mathrm{~W}$ Xe lamp for $7 \mathrm{~h}(\mathbf{f})$ and sample regenerated in ambient air under $400 \mathrm{~W}$ Xe lamp for $2 \mathrm{~h}(\mathbf{g}) . \mathbf{h}-\mathbf{j}, \mathrm{FTIR}$ of pyridine adsorbed over $\mathrm{HPW} / \mathrm{TiO}{ }_{2}(\mathbf{h})$ and fresh (i) and spent $(\mathbf{j}) \mathrm{AgPW} / \mathrm{TiO}_{2}$ showing generation of HPW Brønsted acidity during the methane coupling.

\section{Characterization of the $\mathrm{Ag}-\mathrm{HPW} / \mathrm{TiO}_{2}$ nanocomposites}

X-ray diffraction patterns of $\mathrm{Ag}-\mathrm{HPW} / \mathrm{TiO}_{2}, \mathrm{Ag} / \mathrm{TiO}_{2}, \mathrm{HPW} / \mathrm{TiO}_{2}$, $\mathrm{TiO}_{2}$ and HPW are shown in Fig. 3a. All the samples supported over $\mathrm{TiO}_{2}$ exhibit intense $\mathrm{X}$-ray diffraction peaks of the anatase and rutile phases, while the peaks assigned to the heteropolyacid are only observed in the X-ray diffraction patterns of the pure HPW sample. Neither HPW nor silver diffraction peaks were detected in the Ag-HPW/ $/ \mathrm{TiO}_{2}$ nanocomposite even at a relatively high silver content, which is probably due to the higher dispersion of both HPW and silver species.

The transmission electron microscopy (TEM), scanning transmission electron microscopy high-angle annular dark-field imaging (STEM-HAADF) and STEM energy dispersive X-ray spectroscopy (STEM-EDX) elemental maps of the $\mathrm{Ag}-\mathrm{HPW} / \mathrm{TiO}_{2}$ sample are shown in Fig. 4 and Supplementary Fig. 8. They identify an irregular morphology of $\mathrm{TiO}_{2}$ crystallites with mean sizes of $30-40 \mathrm{~nm}$. The STEM-EDX tungsten maps indicate the formation of a thin layer of HPW (1-2 nm) embedded over the $\mathrm{TiO}_{2}$ crystals. Extremely small silver nanoparticles (probably present as silver oxide species) with a mean diameter of $1.9 \mathrm{~nm}$ are uniformly dispersed on the surface of $\mathrm{HPW} / \mathrm{TiO}_{2}$ (Fig. 4b). Note that the $\mathrm{Ag}-\mathrm{HPW} / \mathrm{TiO}_{2}$ sample could also contain silver cations in the cationic sites of the heteropolyacid, which cannot be conclusively detected by TEM for this particular system.

The temperature-programmed reduction (TPR) profiles of $\mathrm{HPW} / \mathrm{TiO}_{2}$-based nanocomposites are shown in Supplementary Fig. 9. The introduction of silver results in the occurrence of additional low-temperature TPR peaks at $400 \mathrm{~K}$ for both the $\mathrm{Ag} / \mathrm{TiO}_{2}$ and $\mathrm{Ag}-\mathrm{HPW} / \mathrm{TiO}_{2}$ samples, which are attributed to the reduction of silver species:

$$
2 \mathrm{Ag}^{+}+\mathrm{H}_{2} \rightarrow 2 \mathrm{Ag}^{0}+2 \mathrm{H}^{+}
$$

The ultraviolet (UV)-visible diffuse reflectance spectra of $\mathrm{Ag}-\mathrm{HPW} / \mathrm{TiO}_{2}, \mathrm{Ag}-\mathrm{HPW} / \mathrm{SiO}_{2}$ and reference compounds
(Supplementary Fig. 10) exhibit intense absorption in the ultraviolet region. The band gap energy, estimated using Tauc's plots, varies from $2.8 \mathrm{eV}$ to $3.2 \mathrm{eV}$ (refs. ${ }^{42-44}$ ). Note that the value of the band gap in $\mathrm{TiO}_{2}$ is close to that in $\mathrm{HPW}^{34,41}$. Interestingly, a much smaller band gap was observed in Ag-HPW/SiO 2 compared to Ag-HPW/ $\mathrm{TiO}_{2}$. This can be attributed to the lower dispersion and larger domain sizes of HPW on the $\mathrm{SiO}_{2}$ support. Indeed, the band gap in supported oxide clusters and heteropolyacids decreases with the increase in the particle size ${ }^{45,46}$.

To evaluate the influence of UV, visible and infrared light on methane coupling, we conducted photochemical experiments using selected spectral ranges $(280<\lambda<400 \mathrm{~nm}$ and $\lambda>382 \mathrm{~nm}$; Table 1). The Ag- $\mathrm{HPW} / \mathrm{TiO}_{2}$ nanocomposite exhibits a lower reaction rate under visible-infrared irradiation, while the reaction rate increases 90 times upon exposure to the UV light. The excitation of the band gap transfer in $\mathrm{TiO}_{2}$ seems necessary for this photochemical process.

\section{Reaction pathways in photochemical coupling of methane}

To explore the molecular pathways of photochemical methane coupling, $\mathrm{Ag}-\mathrm{HPW} / \mathrm{TiO}_{2}$ was exposed to methane, ethane or a mixture of methane and ethane under irradiation (Fig. 5). Ethane and propane were observed during the photochemical conversion of methane, along with small amounts of $\mathrm{CO}_{2}$. The exposure of Ag-HPW/ $\mathrm{TiO}_{2}$ to ethane under irradiation led to some amounts of butane, while $\mathrm{CO}_{2}$ became the main product. When the reactor contained a mixture of $5 \%$ ethane and $95 \%$ methane, ethane with propane and butane were produced under the Xe lamp irradiation. This is indicative of simultaneous ethane self-coupling and ethane-methane cross-coupling over $\mathrm{Ag}-\mathrm{HPW} / \mathrm{TiO}_{2}$, though the selectivity to higher hydrocarbons in the ethane coupling is much lower, because of the competing complete oxidation of ethane and higher hydrocarbons. The Ag-HPW/TiO ${ }_{2}$ nanocomposite was also exposed to propane under irradiation. No propane coupling was detected, and only $\mathrm{CO}_{2}$ was observed as the reaction product. 

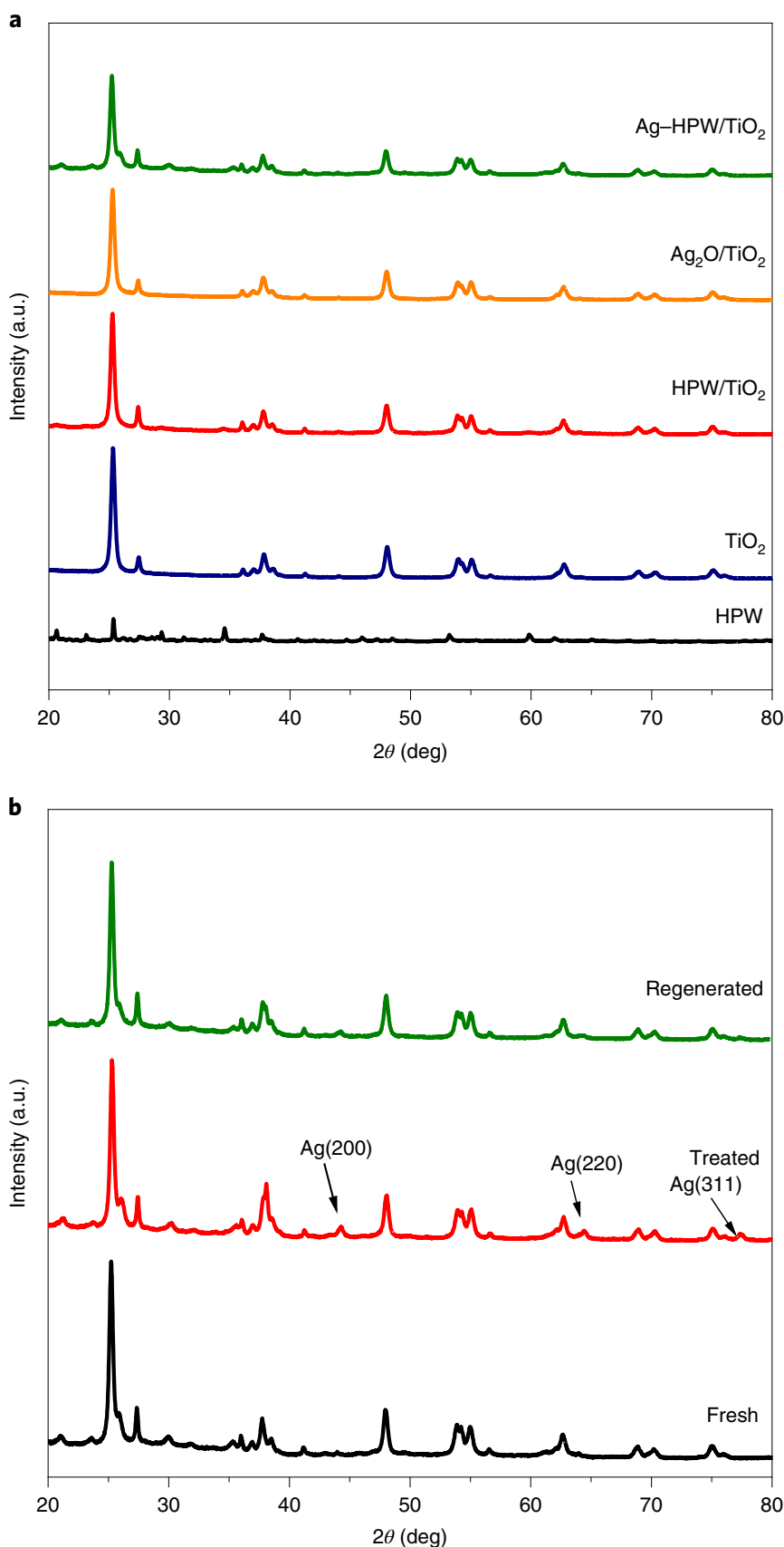

Fig. 3 | X-ray diffraction patterns of nanocomposites. $\mathbf{a}, \mathrm{X}$-ray diffraction patterns of nanocomposites after calcination. $\mathbf{b}, \mathrm{X}$-ray diffraction patterns of fresh, treated (in $0.3 \mathrm{MPa} \mathrm{CH}_{4}$ under $400 \mathrm{~W}$ Xe lamp for $7 \mathrm{~h}$ ) and regenerated (in ambient air under $400 \mathrm{~W}$ Xe lamp for $2 \mathrm{~h}$ ) $\mathrm{Ag}-\mathrm{HPW} / \mathrm{TiO}_{2}$ nanocomposites.

Notably, the addition of hydroquinone, a well-known inhibitor of radical reactions ${ }^{47}$, resulted in a major decrease in the methane conversion over $\mathrm{Ag}-\mathrm{HPW} / \mathrm{TiO}_{2}$, implying that methane oxidative coupling proceeds via radical pathways involving $\mathrm{CH}_{3}$ radicals as intermediates.

The variation of the amount of ethane, propane and $\mathrm{CO}_{2}$ with time during exposure of $\mathrm{Ag}-\mathrm{HPW} / \mathrm{TiO}_{2}$ to light in the presence of methane (Supplementary Fig. 11a) shows a sharp increase in the concentration of ethane during the first $2 \mathrm{~h}$ of the reaction. In the experiments conducted with different amounts of $\mathrm{Ag}-\mathrm{HPW} / \mathrm{TiO}_{2}$, the molar amount of ethane produced was always comparable with that of the silver present in the reactor. Extrapolation to zero reaction time gives an overall selectivity to ethane and propane of greater than $90 \%$ (Supplementary Fig. 11b). The ethane and propane selectivities decrease and $\mathrm{CO}_{2}$ selectivity increases with the reaction time. This suggests $\mathrm{CO}_{2}$ production by the secondary oxidation of ethane, and of propane. Indeed, complete oxidation of ethane under the same conditions proceeds more easily than that of methane (Fig. 5).

To provide further insights into the variation of the silver oxidation state during the reaction, both the freshly calcined Ag-HPW/ $\mathrm{TiO}_{2}$ nanocomposite and its spent counterpart were characterized by X-ray diffraction, X-ray photoemission spectroscopy (XPS) and FTIR. Note that the amount of ethane produced in the second reaction cycle, without sample regeneration, was much lower than in the first cycle (Fig. 2c), most probably because of the lower concentration of silver cations and presence of metallic silver, which is inactive in methane coupling. The nanocomposite exposure to methane under irradiation results in the X-ray diffraction peaks at $2 \theta$ of $44.48^{\circ}, 64.69^{\circ}$ and $77.62^{\circ}$ (Fig. 3b), which correspond to the (200), (220) and (311) planes of metallic silver ${ }^{48}$. When the solid material is regenerated in air under the Xe lamp irradiation for $2 \mathrm{~h}$, the X-ray diffraction peaks of metallic silver almost disappear. XPS and Auger spectroscopy provided further insights into the silver oxidation state in the fresh and spent materials ${ }^{49-53}$. In the Ag Auger spectrum of $\mathrm{Ag}-\mathrm{HPW} / \mathrm{TiO}_{2}$ (Fig. 2d), recorded after treatment in $0.3 \mathrm{MPa} \mathrm{CH}_{4}$ under Xe lamp irradiation for $7 \mathrm{~h}$, the $\mathrm{M}_{4} \mathrm{~N}_{45} \mathrm{~N}_{45}$ $\left(\mathrm{M}_{4} \mathrm{VV}\right)$ peak shifts to a lower binding energy by $1.9 \mathrm{eV}$. For the regenerated sample, the peak returns to its initial position. These results are indicative of the reversible reduction and reoxidation of highly dispersed silver species, which take place under irradiation, respectively in methane or air.

The variation of Brønsted and Lewis acidity during methane coupling was monitored using FTIR experiments with adsorbed pyridine (Py; Fig. 2e). The infrared spectrum of the fresh oxidized $\mathrm{HPW} / \mathrm{TiO}_{2}$ shows the bands of adsorbed Py at 1,540 and $1,444 \mathrm{~cm}^{-1}$ attributed to Py adsorption over the Brønsted and Lewis acid sites ${ }^{54}$ (BAS and LAS), respectively. The $\mathrm{HPW} / \mathrm{TiO}_{2}$ sample contains $166 \mu \mathrm{mol} \mathrm{g}^{-1}$ of BAS and $36 \mu \mathrm{mol} \mathrm{g}^{-1}$ of LAS. The silver salt of HPW deposited over $\mathrm{TiO}_{2}$ is expected to have the highest concentration of silver in the cationic sites of HPW. As expected, the introduction of silver cations results in a decrease in the number of BAS to $10 \mu \mathrm{mol} \mathrm{g}^{-1}$ and increase in the number of LAS to $154 \mu \mathrm{mol} \mathrm{g}^{-1}$ in the freshly calcined nanocomposite. The Py band attributed to LAS shifts to $1,447 \mathrm{~cm}^{-1}$ indicating the formation of LAS associated with low-coordinated $\mathrm{Ag}^{+}$ions. The exposure of $\mathrm{AgPW} / \mathrm{TiO}_{2}$ to methane under irradiation results in the reappearance of the Py bands attributed to BAS following the reduction of silver species:

$$
2 \mathrm{Ag}^{+}+2 \mathrm{CH}_{4} \rightarrow \mathrm{C}_{2} \mathrm{H}_{6}+\mathrm{Ag}^{0}+2 \mathrm{H}^{+}
$$

After the reaction, the number of BAS in $\mathrm{AgPW} / \mathrm{TiO}_{2}$ increased to $104 \mu \mathrm{molg}^{-1}$, while the number of LAS decreased to $83 \mu \mathrm{molg}^{-1}$. The FTIR experiments suggest, therefore, reversible photoreduction and reoxidation of silver ions located in the cationic sites of HPW. The participation of silver cations, located in HPW, in methane selective coupling to ethane is consistent with the very high selectivity to ethane obtained under the Xe lamp irradiation for AgPW/ $\mathrm{TiO}_{2}$ (Fig. 1b). It is also in agreement with the observed decrease in the rate of methane coupling at higher silver contents. Indeed, a higher silver content would result in the lowered concentrations of silver cations and an increased fraction of silver oxide clusters (analogous to the $\mathrm{Ag} / \mathrm{TiO}_{2}$ sample), which are less selective in methane coupling, possibly promoting secondary oxidation. As the coupling reaction involves two $\mathrm{CH}_{3}$ radical species produced via methane activation over silver sites, the proximity between two $\mathrm{Ag}^{+}$sites is likely to affect methane conversion, thereby explaining the lower 

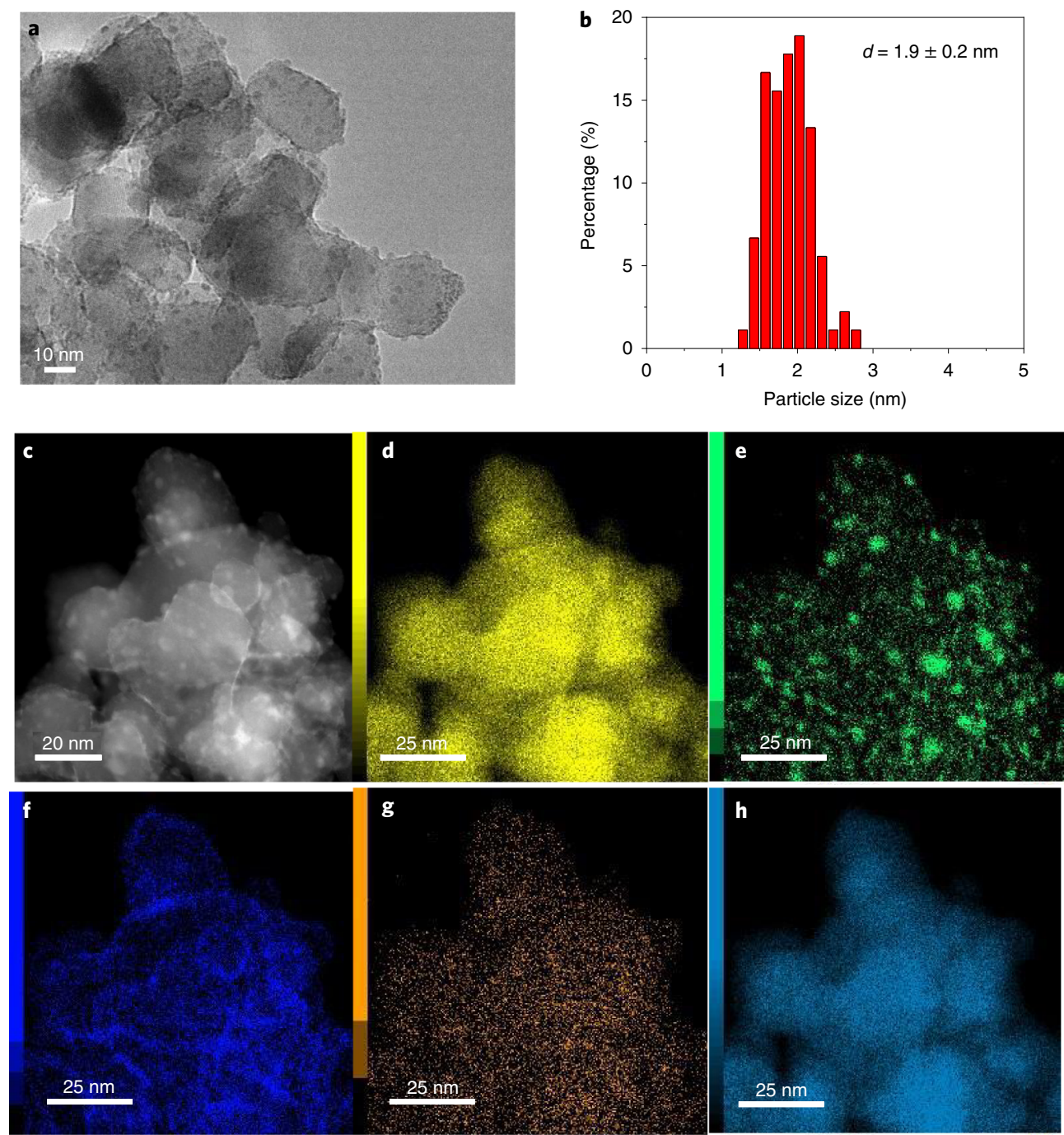

Fig. 4 | TEM and STEM-EDX mapping images of fresh Ag-HPW/ $\mathrm{TiO}_{2}$ sample. a, TEM image of fresh $\mathrm{Ag}-\mathrm{HPW} / \mathrm{TiO}_{2}$ sample. b, Ag particle size distribution (100 particles counted; mean size is $1.9 \mathrm{~nm}$ with a standard deviation of $0.2 \mathrm{~nm}$ ). c-h. STEM-HAADF (c) and corresponding EDX mapping images with intensity scale corresponding to the concentration of the elements and edges: Ti and K edge (d), Ag and L edge (e), W and M edge (f), P and $\mathrm{K}$ edge (g) and $\mathrm{O}$ and $\mathrm{K}$ edge (h).

Table 1 | Rate of photochemical methane coupling measured under irradiation at different spectral ranges

\begin{tabular}{|c|c|c|c|c|}
\hline \multirow{2}{*}{$\begin{array}{l}\text { Spectral range } \\
\text { of irradiation } \\
(\mathrm{nm})\end{array}$} & \multicolumn{2}{|c|}{$\begin{array}{l}\text { Formation rate ( } \mu \mathrm{mol} \\
\left.\mathrm{g}^{-1} \mathrm{~h}^{-1}\right)\end{array}$} & \multirow[t]{2}{*}{$\begin{array}{l}\text { Irradiance } \\
\left(\mathrm{mW} \mathrm{cm} \mathrm{cm}^{-2}\right)\end{array}$} & \multirow{2}{*}{$\begin{array}{l}\text { Formation rate } \\
\text { to power ratio } \\
\left(\mu \mathrm{mol} \mathrm{g}^{-1} \mathrm{~h}^{-1}\right. \\
\left.\mathrm{mW}^{-1} \mathrm{~cm}^{2}\right)\end{array}$} \\
\hline & $\mathrm{C}_{2} \mathrm{H}_{6}$ & $\mathrm{C}_{3} \mathrm{H}_{8}$ & & \\
\hline$>382$ & 0.7 & 0.0 & 94 & 0.0074 \\
\hline $280-400$ & 23 & 1.2 & 38 & 0.64 \\
\hline
\end{tabular}

Reaction conditions: solid sample, $0.1 \mathrm{~g}$; gas phase pressure, $\mathrm{CH}_{4} 0.3 \mathrm{MPa}$; irradiation time, $7 \mathrm{~h}$; light source, Hamamatsu $\mathrm{LC} 8-06 \mathrm{Hg}$-Xe stabilized irradiation lamps with a spectral irradiance in the range 240-600; cut-off filter, visible-infrared $\lambda>382 \mathrm{~nm}$; UV light, $\lambda=280-400 \mathrm{~nm}$.

relative amount of ethane produced from methane at low silver content in $\mathrm{Ag}-\mathrm{HPW} / \mathrm{TiO}_{2}$ nanocomposites (Supplementary Fig. 3).

\section{Synthesis of ethane from methane via photochemical looping}

The reaction tests and characterization suggest a stoichiometric photochemical reaction of methane with cationic silver species selectively yielding ethane and propane. The reaction slows down when cationic silver species are reduced to metallic silver. To conduct continuous ethane synthesis from methane, the reduced silver species should be reversibly reoxidized, so that the spent Ag-HPW/ $\mathrm{TiO}_{2}$ can be reversibly regenerated. Figure 6 a shows the photochemical conversion of methane on the spent $\mathrm{Ag}-\mathrm{HPW} / \mathrm{TiO}$, which was regenerated via exposure to air under irradiation for $7 \mathrm{~h}$. The rate of formation and amounts of ethane, propane and $\mathrm{CO}_{2}$ are the same over the fresh and regenerated $\mathrm{Ag}-\mathrm{HPW} / \mathrm{TiO}_{2}$ nanocomposites following ten reaction-regeneration cycles.

A different response is observed (Supplementary Fig. 12) during the reaction-regeneration cycles for $\mathrm{Ag} / \mathrm{TiO}_{2}$. Methane conversion on this solid results in $\mathrm{CO}_{2}$ and small amounts of ethane. The lower selectivity to ethane in methane conversion over $\mathrm{Ag} / \mathrm{TiO}_{2}$ is consistent with the important role of cationic silver species, rather than the relatively large silver oxide clusters present in $\mathrm{Ag} / \mathrm{TiO}_{2}$, in achieving higher ethane selectivity. In contrast to the $\mathrm{Ag}-\mathrm{HPW} / \mathrm{TiO}_{2}$ nanocomposite, the amounts of $\mathrm{CO}_{2}$ and ethane produced decrease in successive reactionregeneration cycles, indicating irreversible modifications of the $\mathrm{Ag} / \mathrm{TiO}_{2}$ structure. 


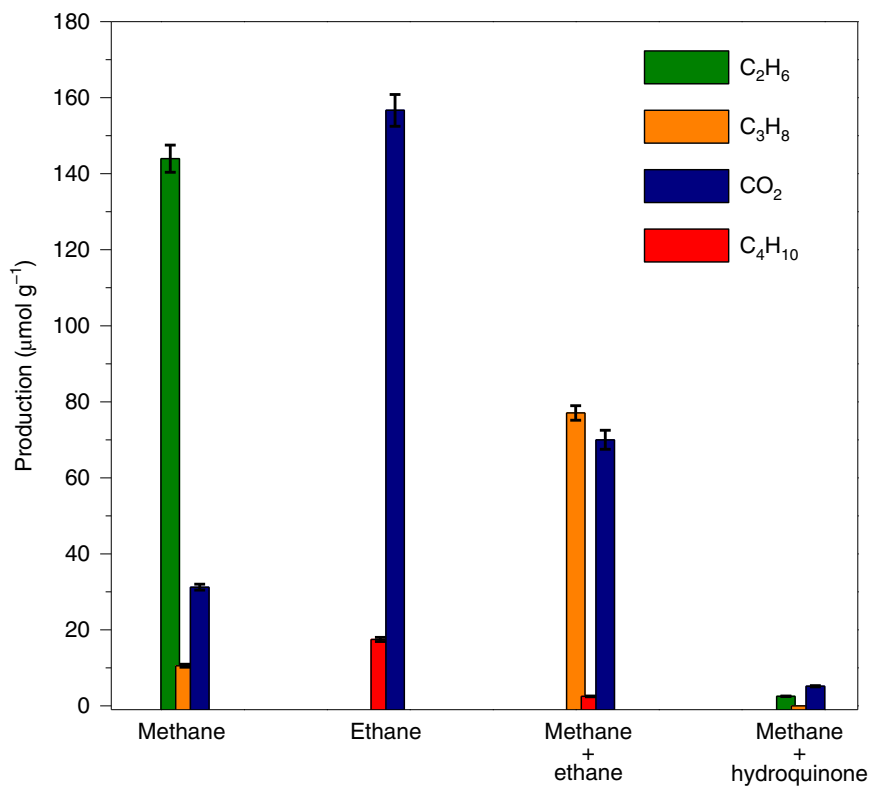

Fig. 5 | Photochemical coupling of methane and ethane on Ag-HPW/ $\mathrm{TiO}_{2}$. Reaction conditions were nanocomposite, $0.1 \mathrm{~g}$; gas phase pressure, $\mathrm{CH}_{4}$, $0.3 \mathrm{MPa}$ (first column); $\mathrm{C}_{2} \mathrm{H}_{6}, 0.3 \mathrm{MPa}$ (second column); $\mathrm{CH}_{4}, 0.285 \mathrm{MPa}$ and $\mathrm{C}_{2} \mathrm{H}_{6}, 0.015 \mathrm{MPa}$ (third column); and $\mathrm{CH}_{4}, 0.3 \mathrm{MPa}$ (fourth column) for the four columns from left to right; and irradiation time, $7 \mathrm{~h}$. Hydroquinone was added as a radical scavenger. The selectivity was calculated on a molar carbon basis. The experiments in each case were performed three times. The error bars represent the standard deviation. The relative standard deviation is within $5 \%$.

Particle size measurements using TEM in fresh and spent $\mathrm{Ag}-$ $\mathrm{HPW} / \mathrm{TiO}_{2}$ and $\mathrm{Ag} / \mathrm{TiO}_{2}$ are displayed in Supplementary Fig. 13. While for the used $\mathrm{Ag} / \mathrm{TiO}_{2}$ sample, the $\mathrm{Ag}$ nanoparticles became noticeably larger after the reaction and a much broader particle size distribution was observed due to sintering $(3.3 \pm 1.3 \mathrm{~nm})$, the $\mathrm{Ag}$ particle size in $\mathrm{Ag}-\mathrm{HPW} / \mathrm{TiO}_{2}$ was essentially unchanged following reaction and regeneration. Thus, the presence of HPW stabilizes high silver dispersion, while silver sintering is the major reason for the decrease in the photochemical activity of $\mathrm{Ag} / \mathrm{TiO}_{2}$ after several reaction-regeneration cycles.

The uncovered stability of the $\mathrm{Ag}-\mathrm{HPW} / \mathrm{TiO}_{2}$ nanocomposite after numerous reaction-regeneration cycles suggests that methane coupling to ethane can be conducted using looping. Previously, the looping strategy has been successfully used for several chemical reactions ${ }^{5-60}$. In this work, we propose a concept of 'photochemical looping' (Fig. 6b). During the methane-coupling step, $\mathrm{CH}_{4}$ is fed into the reactor containing $\mathrm{Ag}-\mathrm{HPW} / \mathrm{TiO}_{2}$ under irradiation. The interaction of methane with silver cationic species leads to the formation of metallic silver, ethane, small amounts of propane and $\mathrm{CO}_{2}$. This reaction also generates BAS, observed by FTIR, in the spent $\mathrm{Ag}-\mathrm{HPW} / \mathrm{TiO}_{2}$ sample. In the regeneration step, $\mathrm{Ag}-\mathrm{HPW} /$ $\mathrm{TiO}_{2}$ is exposed to air under irradiation, which leads to the reoxidation of metallic silver:

$$
2 \mathrm{CH}_{4}+2 \mathrm{Ag}^{+} \rightarrow \mathrm{C}_{2} \mathrm{H}_{6}+2 \mathrm{Ag}^{0}+2 \mathrm{H}^{+} \text {methane coupling step }
$$

$$
4 \mathrm{Ag}^{0}+\mathrm{O}_{2}+4 \mathrm{H}^{+} \rightarrow 4 \mathrm{Ag}^{+}+2 \mathrm{H}_{2} \mathrm{O} \quad \text { silver regeneration step }
$$

In the photochemical looping process, $\mathrm{Ag}-\mathrm{HPW} / \mathrm{TiO}_{2}$ reacts stoichiometrically with methane, yielding ethane and higher
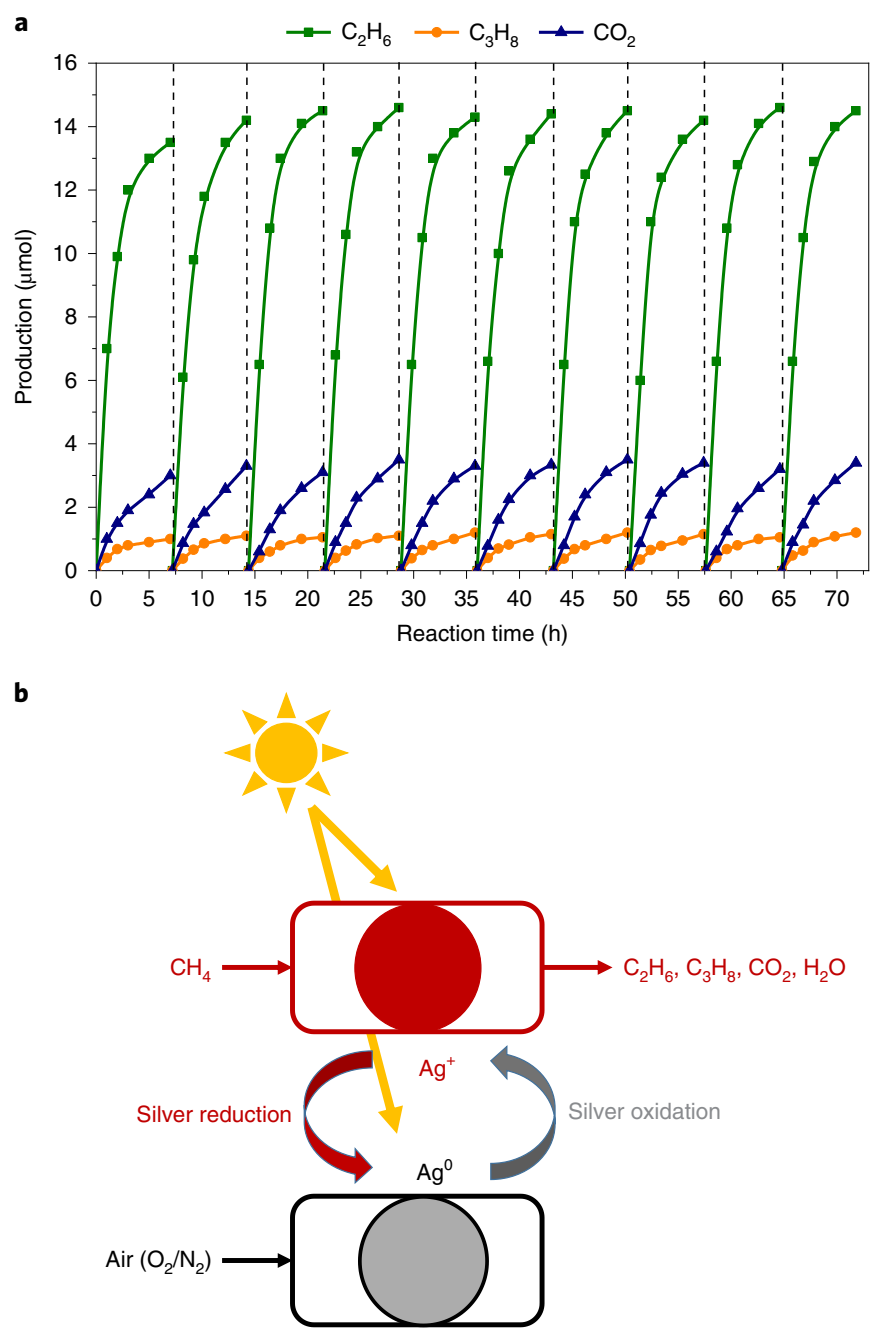

Fig. 6 | Reaction and regeneration of $\mathrm{Ag}-\mathrm{HPW} / \mathrm{TiO}_{2}$. $\mathbf{a}$, Reactionregeneration cycles in methane photochemical coupling on $\mathrm{Ag}-\mathrm{HPW} / \mathrm{TiO}_{2}$. The solid lines are guides to the eye. Dashed lines represent nanocomposite regeneration. $\mathbf{b}$, Schematic description of photochemical looping process. Reaction conditions were nanocomposite, $0.1 \mathrm{~g}$ and gas phase pressure, $\mathrm{CH}_{4}, 0.3 \mathrm{MPa}$.

hydrocarbons. The maximum amount of ethane and higher hydrocarbons produced during the photochemical conversion of methane depends on the amount of cationic silver in the reactor, which is reduced to the metallic state. Metallic silver is then reoxidized to cationic species under irradiation in the presence of air.

Separation of methane and ethane can be prohibitively expensive if the concentration of the target product in the post-reaction mixture is low. This is why we attempted to increase the yield of ethane in the photochemical looping by increasing the ratio of photoactive Ag-HPW/TiO 2 nanocomposite to methane up to 0.33 ( $3 \mu \mathrm{mol}$ of silver and $9 \mu \mathrm{mol}$ of methane). Hence, methane coupling was conducted in a capillary photoreactor with reduced volume (Supplementary Fig. 14). With some decrease in the selectivity to $\mathrm{C}_{2+}$ hydrocarbons, the yield of ethane reached $9 \%$ (on a carbon basis) after $5 \mathrm{~h}$ of exposure to irradiation (Supplementary Figs. 15 and 16).

\section{Conclusion}

Using a silver-hetetopolyacid-titania nanocomposite under illumination at room temperature, we observed the coupling of methane to ethane with high yield and selectivity $(90 \%)$. We find that 
ethane synthesis involves stoichiometric methane reaction with highly dispersed silver cationic species. The photosensitive cationic silver species are reduced to metallic silver during the reaction. Silver cations dispersed in the HPW layer covering $\mathrm{TiO}_{2}$ are essential for the methane coupling to ethane during the reaction. The nanocomposites can be reversibly regenerated by exposure to air at ambient temperature under irradiation. A photochemical looping strategy is proposed as a viable approach for selective quasi-quantitative synthesis of ethane and higher hydrocarbons from methane under irradiation at ambient temperature.

\section{Methods}

Chemicals. Titanium(Iv) oxide (P25, $\mathrm{TiO}_{2}, 99.5 \%$ ), amorphous silica (CARIACT Q-10, Fuji Silysia), urea $\left(\mathrm{NH}_{2} \mathrm{CONH}_{2}, \geq 98.0 \%\right)$, bismuth(III) nitrate pentahydrate $\left(\mathrm{Bi}\left(\mathrm{NO}_{3}\right)_{3} \cdot 5 \mathrm{H}_{2} \mathrm{O}, \geq 98.0 \%\right)$, ammonium metavanadate(v) $\left(\mathrm{NH}_{4} \mathrm{VO}_{3}, 99 \%\right)$, sodium hydroxide $(\mathrm{NaOH}, \geq 98 \%)$, nitric acid $\left(\mathrm{HNO}_{3}, 68.0-70.0 \%\right)$, HPW hydrate $\left(\mathrm{H}_{3} \mathrm{O}_{40} \mathrm{PW}_{12} \cdot x \mathrm{H}_{2} \mathrm{O}, M_{\mathrm{w}}=2880.05\right)$, phosphomolybdic acid hydrate $(\mathrm{H}$ $\left.{ }_{3}\left(\mathrm{P}\left(\mathrm{Mo}_{3} \mathrm{O}_{10}\right)_{4}\right) \cdot x \mathrm{H}_{2} \mathrm{O}, M_{\mathrm{w}}=1825.25\right)$, tungstosilicic acid hydrate $\left(\mathrm{H}_{4}\left(\mathrm{Si}\left(\mathrm{W}_{3} \mathrm{O}_{10}\right.\right.\right.$ )$\left.\left._{4}\right) \cdot x \mathrm{H}_{2} \mathrm{O}, M_{\mathrm{w}}=2878.17\right)$, zinc nitrate hexahydrate $\left(\mathrm{Zn}\left(\mathrm{NO}_{3}\right)_{2} \cdot 6 \mathrm{H}_{2} \mathrm{O}, \geq 99.0 \%\right)$, gallium(III) nitrate hydrate $\left(\mathrm{Ga}\left(\mathrm{NO}_{3}\right)_{3} \cdot x \mathrm{H}_{2} \mathrm{O}, 99.9 \%\right)$, copper(II) nitrate trihydrate $\left(\mathrm{Cu}\left(\mathrm{NO}_{3}\right)_{2} \cdot 3 \mathrm{H}_{2} \mathrm{O}, 99-104 \%\right)$, bismuth(III) nitrate pentahydrate $\left(\mathrm{Bi}\left(\mathrm{NO}_{3}\right)_{3} \cdot 5 \mathrm{H}_{2} \mathrm{O}, \geq 98.0 \%\right)$, silver nitrate $\left(\mathrm{AgNO}_{3}, \geq 99.0 \%\right)$, palladium(II) nitrate hydrate $\left(\mathrm{Pd}\left(\mathrm{NO}_{3}\right)_{2} \cdot x \mathrm{H}_{2} \mathrm{O}, 99.9 \%\right)$, ruthenium(III) chloride hydrate $\left(\mathrm{RuCl}_{3} \cdot x \mathrm{H}_{2} \mathrm{O}\right.$, $38.0-42.0 \% \mathrm{Ru}$ basis), hydrogen hexachloroplatinate(Iv) solution $\left(\mathrm{H}_{2} \mathrm{PtCl}_{6}, 8 \mathrm{wt} \%\right.$ in $\left.\mathrm{H}_{2} \mathrm{O}\right)$ and gold(III) chloride hydrate $\left(\mathrm{HAuCl}_{4} \cdot x \mathrm{H}_{2} \mathrm{O}\right), \sim 50 \%$ Au basis) were purchased from Sigma-Aldrich and used without further purification.

Supports. Commercial amorphous silica (CARIACT Q-10, Fuji Silysia) and $\mathrm{TiO}_{2}$ (P25) together with the synthesized $\mathrm{g}-\mathrm{C}_{3} \mathrm{~N}_{4}$ and $\mathrm{BiVO}_{4}$ were used as supports for the preparation of metal-heteropolyacid nanocomposites. The g- $\mathrm{C}_{3} \mathrm{~N}_{4}$ was fabricated by calcining urea. The powder of urea was calcined in a muffle furnace for $2 \mathrm{~h}$ at $550^{\circ} \mathrm{C}$ with a ramping rate of $10^{\circ} \mathrm{C} \mathrm{min}^{-1}$ in air. After cooling to room temperature, the final light-yellow g- $\mathrm{C}_{3} \mathrm{~N}_{4}$ was obtained. Monoclinic $\mathrm{BiVO}_{4}$ crystals were synthesized by a hydrothermal method. Briefly, the precursors $\mathrm{NH}_{4} \mathrm{VO}_{3}$ $(0.015 \mathrm{~mol})$ and $\mathrm{Bi}\left(\mathrm{NO}_{3}\right)_{3} \cdot 5 \mathrm{H}_{2} \mathrm{O}(0.015 \mathrm{~mol})$ were dissolved in an aqueous nitric acid solution $(2 \mathrm{M})$, and the $\mathrm{pH}$ value of the solution was adjusted to 2.0 with ammonia solution $(14.8 \mathrm{M})$ under continuous stirring. An orange precipitate appeared over time. After that, the suspension was transferred to a Teflon-lined stainless-steel autoclave with a capacity of $100 \mathrm{ml}$ and treated hydrothermally at $473 \mathrm{~K}$ for $24 \mathrm{~h}$. After the autoclave was cooled to room temperature, the yellow powdery sample was separated by filtration, washed with deionized water several times and then dried at $353 \mathrm{~K}$ in air overnight. Finally, the sample was calcined at $773 \mathrm{~K}$ in air for $2 \mathrm{~h}$. The final yellow $\mathrm{BiVO}_{4}$ was obtained.

Synthesis of the metal-HPW/ $\mathrm{TiO}_{2}$ nanocomposites. The metal-HPW/ $/ \mathrm{TiO}_{2}$ nanocomposites were prepared by the two-step impregnation of $\mathrm{TiO}_{2}$. During the impregnation, a fixed amount of $\mathrm{TiO}_{2}$ was first suspended in an anhydrous ethanol solution of HPW hydrate, tungstosilicic acid hydrate $\left(\mathrm{H}_{4}\left(\mathrm{Si}\left(\mathrm{W}_{3} \mathrm{O}_{10}\right)_{4}\right) \cdot x \mathrm{H}_{2} \mathrm{O}, \mathrm{HSiW}\right)$ and phosphomolybdic acid hydrate $\left(\mathrm{H}_{3}\left(\mathrm{P}\left(\mathrm{Mo}_{3} \mathrm{O}_{10}\right)_{4}\right) \cdot x \mathrm{H}_{2} \mathrm{O}, \mathrm{HPMo}\right)$. The HPW to $\mathrm{TiO}_{2}$ ratio varied from 0.15 to 1.2 . The $\mathrm{HPW} / \mathrm{TiO}_{2}\left(\mathrm{HPW} / \mathrm{TiO}_{2}\right.$ ratio $\left.=0.6\right)$ sample was obtained by stirring. The resulting material was then dried at $353 \mathrm{~K}$ for $12 \mathrm{~h}$. Next, the Ag-HPW/TiO 2 sample was prepared by incipient wetness impregnation of the $\mathrm{HPW} / \mathrm{TiO}_{2}$ support with aqueous solutions of silver nitrate $\left(\mathrm{AgNO}_{3}\right)$. Other metal-HPW $/ \mathrm{TiO}_{2}$ composites were prepared using impregnation with the aqueous solutions of relevant salts. The target metal content in the final materials was $6 \mathrm{wt} \%$. After the second impregnation, the samples were dried overnight at $373 \mathrm{~K}$ Then, they were calcined in air at $300^{\circ} \mathrm{C}$ for $3 \mathrm{~h}$ with the $2^{\circ} \mathrm{C} \mathrm{min}{ }^{-1}$ temperature ramp. The samples were labelled as $\mathrm{M}-\mathrm{HPW} / \mathrm{TiO}_{2}$, where $\mathrm{M}$ stands for $\mathrm{Zn}, \mathrm{Cu}, \mathrm{Ga}$, $\mathrm{Bi}, \mathrm{Ru}, \mathrm{Pd}, \mathrm{Pt}$, Au or Ag.

\section{Preparation of the reference silver salt of $\mathrm{HPW}$ deposited on $\mathrm{TiO}_{2}(\mathrm{AgPW} /$}

$\mathrm{TiO}_{2}$ ). First, a fixed amount of HPW hydrate was dissolved in ethanol and mixed with silver nitrate aqueous solution. The precipitate silver salt was filtered out and mixed with the necessary amount of $\mathrm{TiO}_{2}$ to provide the same amount of $\mathrm{Ag}$ as in Ag-HPW/ $/ \mathrm{TiO}_{2}$. The obtained sample was dried overnight at $353 \mathrm{~K}$ and calcined at $473 \mathrm{~K}$ in an oven.

Characterization. A combination of techniques was used for extensive characterization of the solids. The X-ray powder diffraction patterns were measured in the $5-80^{\circ}(2 \theta)$ range using $\mathrm{Cu} \mathrm{K}_{\alpha}$ radiation $(\lambda=0.1538 \mathrm{~nm})$ on a Bruker AXS D8 instrument. A PerkinElmer Lambda 650S UV-visible spectrometer with an integrating sphere covered with $\mathrm{BaSO}_{4}$ as a reference was used for diffuse reflectance UV-visible spectra measurements. The BET surface area was determined by low-temperature $\mathrm{N}_{2}$ adsorption using a Micromeritics TriStar II PLUS automated system. The TEM observations were performed on a Tecnai instrument equipped with a lanthanum hexaboride (LaB6) crystal and a double-corrected Cold FEG ARM Jeol 200 field emission gun, operating at $200 \mathrm{kV}$.
Prior to the analysis, the samples were dispersed by ultrasound in ethanol for $5 \mathrm{~min}$, and a drop of the suspension was deposited onto a carbon membrane on a 300 mesh copper grid. The microscopy-based chemical analyses were carried out in the scanning TEM mode using a $100 \mathrm{~mm}$ Centurio detector for the EDX. The point-to-point resolution was $0.9 \AA$ under the STEM mode. The EDX elemental maps were obtained using a scanning time of $20 \mu$ s per pixel for imaging and $0.05 \mu$ s per pixel for EDX $(256 \times 256$ pixel maps $)$, with a $0.1 \mathrm{~nm}$ probe size and a current of $120 \mathrm{pA}$. To achieve a high signal to noise ratio, the chemical maps were acquired for at least $60 \mathrm{~min}$, along which a cross-correlation algorithm was applied every $30 \mathrm{~s}$ to correct the specimen spatial drift.

The $\mathrm{H}_{2}$-TPR was carried out using the AutoChem II 2920 apparatus (Micromeritics) in a flow of $\mathrm{H}_{2} / \mathrm{Ar}\left(5 \mathrm{vol} . \% \mathrm{H}_{2}, 30 \mathrm{~cm}^{3} \mathrm{~min}^{-1}\right)$ with the temperature rate of $10^{\circ} \mathrm{C} \mathrm{min}{ }^{-1}$.

FTIR spectra were collected using a Thermo Nicolet 8700 spectrometer equipped with a mercury-cadmium-telluride (MCT) detector using a range of resolution settings ( 1 to $4 \mathrm{~cm}^{-1}$ ). The analysed samples were pressed in $\sim 20-30 \mathrm{mg}$ (diameter $=13 \mathrm{~mm}$ ) self-supporting discs and treated in vacuum at $80^{\circ} \mathrm{C}$. Py adsorption was performed by adding 5 torr of Py with subsequent treatment under vacuum. The spectra were analysed using specialized Thermo software (Omnic). The numbers of BAS and LAS were calculated from the Py adsorption data. The molar extinction coefficients of $1.65 \mathrm{~cm} \mathrm{~mol}^{-1}$ for BAS-Py complexes and $1.87 \mathrm{~cm} \mu \mathrm{mol}^{-1}$ for LAS-Py complexes were used for the quantification of Brønsted and Lewis acid sites.

A Kratos Axis spectrometer, equipped with an aluminium monochromator for a $1,486.6 \mathrm{eV}$ source working at $120 \mathrm{~W}$, was used in this work for the XPS acquisition. The value of the $\mathrm{Ag} 3 d_{5 / 2}$ binding energy does not allow a clear discrimination of the silver oxidation state. The $\mathrm{Ag} 3 d_{5 / 2}$ lines of metallic $\mathrm{Ag}$ and silver oxide are positioned at $368.2 \mathrm{eV}$ and $367.8 \mathrm{eV}$, respectively ${ }^{50}$. Such a small difference in the binding energy is often beyond the resolution of the XPS spectrometer; therefore Auger spectroscopy measurements were carried out. The energy of Auger peaks for $\mathrm{M}_{4} \mathrm{VV}$ is known to be particularly sensitive to the oxidation state, differing by more than $1 \mathrm{eV}$ for $\mathrm{Ag}^{+}$versus $\mathrm{Ag}^{0}$ (refs. ${ }^{51-53}$ ). The binding energies were corrected with respect to $\mathrm{C} 1 s(284.6 \mathrm{eV})$; they were estimated within $\pm 0.2 \mathrm{eV}$. The positions of all Auger peaks were aligned by the $\mathrm{C} 1 \mathrm{~s}$ peak, and a Shirley background was subtracted.

Photochemical tests. A homemade stainless-steel batch reactor (volume $\approx 250 \mathrm{ml}$ ) with a quartz window on the top of the reactor was used for the photochemical methane conversion (Supplementary Fig. 1). All the photochemical tests were performed at ambient temperature. The light source for most experiments was a $400 \mathrm{~W}$ Xe lamp (Newport) characterized by a broad emission spectrum (from $\sim 200$ to $1,100 \mathrm{~nm}$ ). A Hamamatsu spot light source LC8-06 Hg-Xe lamp, emitting between 240 and $600 \mathrm{~nm}$, equipped with a quartz light-guide to deliver a stable and uniform illumination of the sample, were used for measuring the QE. A Hamamatsu optical filter was used for selecting the spectral range. The irradiance values measured by an optical power meter (Newport PMKIT) were 94 and $38 \mathrm{~mW} \mathrm{~cm}^{-2}$ in the ranges of $>382 \mathrm{~nm}$ and $280-400 \mathrm{~nm}$, respectively.

A sample of $0.1 \mathrm{~g}$ of a solid nanocomposite was placed on a quartz glass holder at the bottom of the reactor. Then, the reactor was evacuated using a vacuum pump and filled with $\mathrm{CH}_{4}$. The methane pressure was increased up to $0.3 \mathrm{MPa}$ and the reactor was kept in the dark for $1 \mathrm{~h}$ to ensure an adsorption-desorption equilibrium between the solid material and reactants. Subsequently, the reactor was irradiated by the $400 \mathrm{~W}$ Xe lamp. The reaction time was varied between 2 and $20 \mathrm{~h}$.

A photoreactor with reduced volume was used to obtain high methane conversion (Supplementary Fig. 14). This photoreactor was a quartz capillary with an internal diameter of $0.8 \mathrm{~mm}$ and length of $50 \mathrm{~mm}$, attached to a metallic frame with epoxy glue and filled with methane $(P=0.2 \mathrm{MPa})$. The weight of the Ag$\mathrm{HPW} / \mathrm{TiO}_{2}$ nanocomposite in the photoreactor was $5 \mathrm{mg}$.

The reaction products $\left(\mathrm{C}_{2} \mathrm{H}_{6}, \mathrm{C}_{3} \mathrm{H}_{8}\right.$ and $\left.\mathrm{CO}_{2}\right)$ were analysed by $\mathrm{GC}$ (PerkinElmer Clarus $580 \mathrm{GC}$ ) with helium as the carrier gas. The standard deviation in GC analysis was close to 5\%. The reactors were attached to an online GC injection valve, and the gaseous products were directly injected into the GC. PoraBOND Q and ShinCarbon ST 100/120 columns, a flame ionization detector and a thermal conductivity detector were employed for the analysis.

Measurement of quantum efficiency. The QE at $362 \mathrm{~nm}$ in methane coupling was measured for the $6 \mathrm{wt} \% \mathrm{Ag}-\mathrm{HPW} / \mathrm{TiO}_{2}$ nanocomposite. The following equation was used for the QE $(\eta)$ calculation:

$$
\eta=\frac{R(\text { electron }) N_{\mathrm{A}}}{I S t / E_{\lambda}} \times 100 \%
$$

where $N_{\mathrm{A}}, I, S$ and $t$ stand for the Avogadro's constant, light irradiance on the sample (in $\mathrm{W} \mathrm{cm}^{-2}$ ), irradiation area (in $\mathrm{cm}^{-2}$ ) and reaction time (in s), respectively. $E_{\lambda}$ (in J) is given by $h c / \lambda(\lambda=362 \mathrm{~nm}) . R$ (electron) represents the number of electrons used in the formation of the products. $R_{\mathrm{C} 2}$ (electron) and $R_{\mathrm{C} 3}$ (electron) are the number of moles of electrons used for the formations of $\mathrm{C}_{2} \mathrm{H}_{6}$ and $\mathrm{C}_{3} \mathrm{H}_{8}$, respectively. $R$ (electron $)=R_{\mathrm{C} 2}$ (electron $)+R_{\mathrm{C} 3}$ (electron $)=2 n\left(\mathrm{C}_{2} \mathrm{H}_{6}\right)+3 n\left(\mathrm{C}_{3} \mathrm{H}_{8}\right)$, where $n\left(\mathrm{C}_{2} \mathrm{H}_{6}\right)$ and $n\left(\mathrm{C}_{3} \mathrm{H}_{8}\right)$ are the number of moles of $\mathrm{C}_{2} \mathrm{H}_{6}$ and $\mathrm{C}_{3} \mathrm{H}_{8}$, respectively. 


\section{Data availability}

The authors declare that the data supporting the findings of this study are available within the paper, Supplementary Information and Source Data files.

Received: 19 August 2019; Accepted: 14 April 2020;

Published online: 18 May 2020

\section{References}

1. McFarland, E. Unconventional chemistry for unconventional natural gas. Science 338, 340-342 (2012).

2. Tang, P., Zhu, Q., Wu, Z. \& Ma, D. Methane activation: the past and future. Energ. Environ. Sci. 7, 2580-2591 (2014).

3. Taarning, E. et al. Zeolite-catalyzed biomass conversion to fuels and chemicals. Energ. Environ. Sci. 4, 793-804 (2011).

4. Dapsens, P. Y., Mondelli, C. \& Pérez-Ramírez, J. Biobased chemicals from conception toward industrial reality: lessons learned and to be learned. ACS Catal. 2, 1487-1499 (2012).

5. Kondratenko, E. V., Mul, G., Baltrusaitis, J., Larrazábal, G. O. \& Pérez-Ramírez, J. Status and perspectives of $\mathrm{CO}_{2}$ conversion into fuels and chemicals by catalytic, photocatalytic and electrocatalytic processes. Energ. Environ. Sci. 6, 3112-3135 (2013).

6. Kondratenko, E. V. et al. Methane conversion into different hydrocarbons or oxygenates: current status and future perspectives in catalyst development and reactor operation. Catal. Sci. Technol. 7, 366-381 (2017).

7. Kaygusuz, K. Global energy issues, climate change and wind power for clean and sustainable energy development. J. Eng. Res. Appl. Sci. 4, 317-327 (2015)

8. Farrell, B. L., Igenegbai, V. O. \& Linic, S. A viewpoint on direct methane conversion to ethane and ethylene using oxidative coupling on solid catalysts. ACS Catal. 6, 4340-4346 (2016).

9. Hammond, C., Conrad, S. \& Hermans, I. Oxidative methane upgrading. ChemSusChem 5, 1668-1686 (2012).

10. Choudhary, T. V. \& Choudhary, V. R. Energy-efficient syngas production through catalytic oxy-methane reforming reactions. Angew. Chem. Int. Ed. 47, 1828-1847 (2008).

11. Song, H., Meng, X. G., Wang, Z. J., Liu, H. M. \& Ye, J. H. Solar-energy-mediated methane conversion. Joule 3, 1606-1636 (2019).

12. Jang, W. J., Shim, J. O., Kim, H. M., Yoo, S. Y. \& Roh, H. S. A review on dry reforming of methane in aspect of catalytic properties. Catal. Today 324, 15-26 (2019).

13. Lunsford, J. H. Catalytic conversion of methane to more useful chemicals and fuels: a challenge for the 21st century. Catal. Today 63, 165-174 (2000).

14. Webb, J. R., Bolaño, T. \& Gunnoe, T. B. Catalytic oxy-functionalization of methane and other hydrocarbons: fundamental advancements and new strategies. ChemSusChem 4, 37-49 (2011).

15. Wang, B., Albarracín-Suazo, S., Pagán-Torres, Y. \& Nikolla, E. Advances in methane conversion processes. Catal. Today 285, 147-158 (2017).

16. Keller, G. \& Bhasin, M. Synthesis of ethylene via oxidative coupling of methane: I. Determination of active catalysts. J. Catal. 73, 9-19 (1982).

17. Zavyalova, U., Holena, M., Schlögl, R. \& Baerns, M. Statistical analysis of past catalytic data on oxidative methane coupling for new insights into the composition of high-performance catalysts. Chem CatChem 3 , 1935-1947 (2011)

18. Stansch, Z., Mleczko, L. \& Baerns, M. Comprehensive kinetics of oxidative coupling of methane over the $\mathrm{La}_{2} \mathrm{O}_{3} / \mathrm{CaO}$ catalyst. Ind. Eng. Chem. Res. 36, 2568-2579 (1997).

19. Lunsford, J. H. The catalytic oxidative coupling of methane. Angew. Chem. Int. Ed. 34, 970-980 (1995).

20. Kondratenko, E.V. \& Baerns, M. in Handbook of Heterogeneous Catalysis 2nd edn, Vol. 6 (eds Ertl, G. et al.) 3010-3023 (Wiley-VCH Verlag GmbH \& Co. $\mathrm{KGaA}, 2008)$.

21. Kuo, J., Kresge, C. \& Palermo, R. Evaluation of direct methane conversion to higher hydrocarbons and oxygenates. Catal. Today 4, 463-470 (1989).

22. Kanai, M. Photocatalytic upgrading of natural gas. Science 361, 647-648 (2018).

23. Yuliati, L. \& Yoshida, H. Photocatalytic conversion of methane. Chem. Soc. Rev. 37, 1592-1602 (2008).

24. Yuliati, L., Hamajima, T., Hattori, T. \& Yoshida, H. Highly dispersed Ce (III) species on silica and alumina as new photocatalysts for non-oxidative direct methane coupling. Chem. Commun. 38, 4824-4826 (2005).

25. Yuliati, L., Tsubota, M., Satsuma, A., Itoh, H. \& Yoshida, H. Photoactive sites on pure silica materials for nonoxidative direct methane coupling. J. Catal. 238, 214-220 (2006)

26. Yuliati, L., Hattori, T., Itoh, H. \& Yoshida, H. Photocatalytic nonoxidative coupling of methane on gallium oxide and silica-supported gallium oxide. J. Catal. 257, 396-402 (2008).

27. Li, L. et al. Efficient sunlight-driven dehydrogenative coupling of methane to ethane over a $\mathrm{Zn}^{+}$-modified zeolite. Angew. Chem. Int. Ed. 50, 8299-8303 (2011)
28. Li, L. et al. Synergistic effect on the photoactivation of the methane $\mathrm{C}-\mathrm{H}$ bond over $\mathrm{Ga}^{3+}$-modified ETS-10. Angew. Chem. Int. Ed. 51, 4702-4706 (2012).

29. Meng, L. S. et al. Gold plasmon-induced photocatalytic dehydrogenative coupling of methane to ethane on polar oxide surfaces. Energ. Environ. Sci. 11, 294-298 (2018).

30. Wu, S. Q. et al. Ga-doped and Pt-loaded porous $\mathrm{TiO}_{2}-\mathrm{SiO}_{2}$ for photocatalytic nonoxidative coupling of methane. J. Am. Chem. Soc. 141, 6592-6600 (2019).

31. Yu, L., Shao, Y. \& Li, L. Direct combination of hydrogen evolution from water and methane conversion in a photocatalytic system over $\mathrm{Pt} / \mathrm{TiO}_{2}$. Appl. Catal. B Environ. 204, 216-223 (2017).

32. Yu, L. \& Li, D. Photocatalytic methane conversion coupled with hydrogen evolution from water over $\mathrm{Pd} / \mathrm{TiO}_{2}$. Catal. Sci. Techn. 7, 635-640 (2017)

33. Amano, F. et al. Photoelectrochemical homocoupling of methane under blue light irradiation. ACS Energy Lett. 4, 502-507 (2019).

34. Yu, X., de Waele, V., Löfberg, A., Ordomsky, V. \& Khodakov, A. Y. Selective photocatalytic conversion of methane into carbon monoxide over zinc-heteropolyacid-titania nanocomposites. Nat. Commun. 10, 700 (2019).

35. Yoshida, H. et al. Active Ag species in MFI zeolite for direct methane conversion in the light and dark. Res. Chem. Intermed. 29, 897-910 (2003).

36. Ozin, G. A. \& Hugues, F. Selective photoactivation of carbon-hydrogen bonds in paraffinic hydrocarbons. Dimerization of alkanes. J. Phys. Chem. 86, 5174-5179 (1982).

37. Wang, H. et al. Semiconductor heterojunction photocatalysts: design, construction, and photocatalytic performances. Chem. Soc. Rev. 43, 5234-5244 (2014)

38. Sun, Z., Zhang, Y., Li, N., Xu, L. \& Wang, T. Enhanced photoconductivity of a polyoxometalate- $\mathrm{TiO}_{2}$ composite for gas sensing applications. J. Mater. Chem. C. 3, 6153-6157 (2015).

39. Meng, P. et al. Positive effects of phosphotungstic acid on the in-situ solid-state polymerization and visible light photocatalytic activity of polyimide-based photocatalyst. Appl. Catal. B 226, 487-498 (2018).

40. Tran, P. D., Wong, L. H., Barberbcd, J. \& Loo, J. S. C. Recent advances in hybrid photocatalysts for solar fuel production. Energy Environ. Sci. 5, 5902-5918 (2002).

41. Yu, X., Moldovan, S., Ordomsky, V. V. \& Khodakov, A. Y. Design of core-shell titania-heteropolyacid-metal nanocomposites for photocatalytic reduction of $\mathrm{CO}_{2}$ to $\mathrm{CO}$ at ambient temperature. Nanoscale Adv. 1, 4321-4330 (2019).

42. Gondal, M., Hameed, A., Yamani, Z. \& Arfaj, A. Photocatalytic transformation of methane into methanol under UV laser irradiation over $\mathrm{WO}_{3}, \mathrm{TiO}_{2}$ and $\mathrm{NiO}$ catalysts. Chem. Phys. Lett. 392, 372-377 (2004).

43. Murcia-López, S. et al. Controlled photocatalytic oxidation of methane to methanol through surface modification of beta zeolites. ACS Catal. 7, 2878-2885 (2017).

44. Murcia-López, S., Villa, K., Andreu, T. \& Morante, J. R. Partial oxidation of methane to methanol using bismuth-based photocatalysts. ACS Catal. 4, 3013-3019 (2014)

45. Barton, D. G., Shtein, M., Wilson, R. D., Soled, S. L. \& Iglesia, E. Structure and electronic properties of solid acids based on tungsten oxide nanostructures. J. Phys. Chem. B 103, 630-640 (1999).

46. Weber, R. S. Effect of local structure on the UV-visible absorption edges of molybdenum oxide clusters and supported molybdenum oxides. J. Catal. 151, 470-474 (1995)

47. Nakarada, Đ. \& Petković, M. Mechanistic insights on how hydroquinone disarms OH and OOH radicals. Int. J. Quantum Chem. 118, e25496 (2018).

48. Kalishwaralal, K., Deepak, V., Ramkumarpandian, S., Nellaiah, H. \& Sangiliyandi, G. Extracellular biosynthesis of silver nanoparticles by the culture supernatant of Bacillus licheniformis. Mater. Lett. 62, 4411-4413 (2008).

49. Prieto, P. et al. XPS study of silver, nickel and bimetallic silver-nickel nanoparticles prepared by seed-mediated growth. Appl. Surf. Sci. 258, 8807-8813 (2012).

50. Gaarenstroom, S. \& Winograd, N. Initial and final state effects in the ESCA spectra of cadmium and silver oxides. J. Chem. Phys. 67, 3500-3506 (1977).

51. Anthony, M. \& Seah, M. XPS: energy calibration of electron spectrometers. 1 -An absolute, traceable energy calibration and the provision of atomic reference line energies. Surf. Interface Anal. 6, 95-106 (1984).

52. Samokhvalov, A., Nair, S., Duin, E. C. \& Tatarchuk, B. J. Surface characterization of Ag/titania adsorbents. Appl. Surf. Sci. 256, 3647-3652 (2010).

53. Fernández, A. \& González-Elipe, A. In situ XPS study of the photoassisted reduction of noble-metal cations on $\mathrm{TiO}_{2}$. Appl. Surf. Sci. 69, 285-289 (1993).

54. Parry, E. P. An infrared study of pyridine adsorbed on acidic solids. Characterization of surface acidity. J. Catal. 2, 371-379 (1963). 
55. Adanez, J., Abad, A., Garcia-Labiano, F., Gayan, P. \& Luis, F. Progress in chemical-looping combustion and reforming technologies. Prog. Energ. Combust. Sci. 38, 215-282 (2012).

56. Bhavsar, S., Najera, M., Solunke, R. \& Veser, G. Chemical looping: to combustion and beyond. Catal. Today 228, 96-105 (2014).

57. Vorrias, I. et al. Calcium looping for $\mathrm{CO}_{2}$ capture from a lignite fired power plant. Fuel 113, 826-836 (2013).

58. Galvita, V. V., Poelman, H. \& Marin, G. B. Combined chemical looping for energy storage and conversion. J. Power Sources 286, 362-370 (2015).

59. Buelens, L. C., Galvita, V. V., Poelman, H., Detavernier, C. \& Marin, G. B. Super-dry reforming of methane intensifies $\mathrm{CO}_{2}$ utilization via Le Chatelier's principle. Science 354, 449-452 (2016).

60. Zhang, J., Haribal, V. \& Li, F. Perovskite nanocomposites as effective $\mathrm{CO}_{2}$-splitting agents in a cyclic redox scheme. Sci. Adv. 3, e1701184 (2017).

\section{Acknowledgements}

We thank L. Burylo, P. Simon and M. Frère for help with X-ray diffraction and XPS measurements. X.Y. and D.H thank the Chinese scholarship council for providing stipends for their $\mathrm{PhD}$ studies in France. We thank Chevreul Institute (FR 2638), Ministère de l'Enseignement Supérieur, de la Recherche et de l'Innovation, Hauts-de-France Region and FEDER for supporting and partially funding this work GENESIS is supported by the Région Haute-Normandie, Métropole Rouen Normandie, CNRS via LABEX EMC3 and French National Research Agency as a part of the programme 'Investissements d'avenir' with the reference ANR-11-EQPX-0020.

\section{Author contributions}

X.Y., V.V.O. and A.Y.K. conceived the idea for this work. All authors contributed to the design of the experimental set-up and experimental procedures. X.Y. prepared the nanocomposite materials, collected the data and performed ex situ characterization. X.Y, D.W., V.L.Z. and V.V.O performed the infrared measurements. S.M. performed nanocomposite characterization using imaging techniques. V.L.Z., A.Y.K and X.Y. designed the capillary photoreactor and performed the high-conversion methane experiments. D.H. synthesized the silver salt of HPW and conducted additional experiments in order to address the reviewer comments. X.Y. and A.Y.K. wrote the draught, and all the authors worked on improving the manuscript.

\section{Competing interests}

The authors declare no competing interests.

\section{Additional information}

Supplementary information is available for this paper at https://doi.org/10.1038/ s41560-020-0616-7.

Correspondence and requests for materials should be addressed to V.V.O. or A.Y.K.

Reprints and permissions information is available at www.nature.com/reprints.

Publisher's note Springer Nature remains neutral with regard to jurisdictional claims in published maps and institutional affiliations.

(c) The Author(s), under exclusive licence to Springer Nature Limited 2020 